\title{
Genital ulcer disease: Accuracy of clinical diagnosis and strategies to improve control in Durban, South Africa
}

\author{
N O'Farrell, A A Hoosen, K D Coetzee, J van den Ende
}

\begin{abstract}
Objective-To investigate the accuracy of clinical diagnosis in genital ulcer disease (GUD); to devise management strategies for improving the control of GUD and thereby limit the spread of HIV-1 infection.
\end{abstract}

Design-Clinical and microbiological assessment of GUD in men and women. The index of suspicion, diagnostic accuracy, diagnostic efficiency and positive and negative predictive values of a clinical diagnosis were investigated.

Setting-City Health Sexually Transmitted Diseases Clinic, King Edward VIII Hospital, Durban, South Africa. Participants-100 men and 100 women with genital ulcers.

Results-The accuracy of a clinical diagnosis was, in men: lymphogranuloma venereum (LGV) $66 \%$, donovanosis $63 \%$, chancroid $42 \%$, genital herpes $39 \%$, primary syphilis $32 \%$, mixed infections $8 \%$, and in women; secondary syphilis $94 \%$, donovanosis $83 \%$, genital herpes $60 \%$, primary syphilis $58 \%$, chancroid $57 \%$, LGV $40 \%$, mixed infections $14 \%$. Overall, diagnostic efficiency was greater in women than in men. When compared with other causes of GUD, donovanosis ulcers bled to the touch and were larger and not usually associated with inguinal lymphadenopathy. In women, extensive vulval condylomata lata were readily differentiated from all other causes of GUD. Conclusion-A clinical diagnosis in genital ulceration was less accurate in men than in women. The diagnostic accuracies for donovanosis and secondary syphilis were relatively high but for most other conditions were low. Differences between clinical and laboratory diagnostic accuracies may reflect similarities between the clinical appearances of the various causes of GUD, the presence of mixed infections, atypical ulceration due to longstanding disease, and insensitive laboratory tests. In this community all large ulcers should be treated empirically for syphilis and donovanosis. Uncircumcised men with GUD are an important HIV core or "superspreader" group locally, and prevention strategies should include counselling and health education in the light of the inaccuracy of clinical diagnosis found in this study. The development of rapid accurate tests for GUD is urgently required.

(Genitourin Med 1994;70:7-11)
Introduction

Genital ulcer disease (GUD) is a common clinical problem in many parts of East, Central and Southern Africa. Because of a lack of adequate laboratory facilities in these countries most cases are diagnosed clinically. Although the classical signs of the ulcerative lesions caused by sexually transmitted diseases are well documented, presentation of cases in the field is often atypical and clinical assessment may be inaccurate.

GUD is now well established as a risk factor for HIV transmission. Indeed, one study based on data from Kenya puts the proportion of HIV infections in men attributable to GUD as high as $75-98 \% .{ }^{1}$ In Durban, where the HIV epidemic is escalating rapidly, all the STD causes of GUD are prevalent ${ }^{23}$ and an increased risk of HIV infection in men is associated with GUD. ${ }^{4}$ WHO have recommended that HIV control programmes incorporate strategies for limiting the transmission of STDs and have identified the effectiveness of control of GUD in reducing sexual transmission of HIV-1 as one of the main areas needing further research. ${ }^{5}$ This study was undertaken to investigate the accuracy of clinical diagnosis of GUD in Durban and to formulate strategies to improve the control of GUD in the local community.

Patients and methods

The study subjects were 100 Zulu men and 100 Zulu women with GUD attending the City Health STD clinic at King Edward VIII Hospital, Durban, between August 1988 and January 1989 who had not received antibiotics during the previous two weeks. Ulcers were assessed by one physician (NO'F) and the most likely diagnosis was recorded prospectively using the following clinical characteristics; primary syphilis-well-demarcated, indurated, non-tender, non-purulent; chancroid-small, painful, irregular, raised edges, purulent base; donovanosis-large, beefy-red, well-demarcated, vascular, nonpainful; genital herpes-small, painful, superficial, multiple; lymphogranuloma venereum (LGV) - small, deep, single, large painful inguinal lymph glands; secondary syphilisnon-painful, multiple, pearly-grey papules/ confluent raised plaques. Demographic characteristics and details of physical examination of the patients studied and microbiological methods are recorded elsewhere. ${ }^{23}$ In addition a laboratory-based diagnosis of secondary syphilis, as opposed to primary syphilis, was made by using the following three criteria: rapid plasma reagin (RPR) titre 
Table 1 Clinical and laboratory diagnosis in 100 men with genital ulcer disease

\begin{tabular}{|c|c|c|c|c|c|c|c|}
\hline \multirow[b]{2}{*}{ Laboratory diagnosis } & \multirow[b]{2}{*}{ Number } & \multicolumn{6}{|c|}{ Clinical diagnosis } \\
\hline & & $\begin{array}{l}\text { Syphilis } \\
n=13\end{array}$ & $\begin{array}{l}\text { Chancroid } \\
n=36\end{array}$ & $\begin{array}{l}\text { Genital } \\
\text { herpes } \\
n=22\end{array}$ & $\begin{array}{l}\text { Donovanosis } \\
n=11\end{array}$ & $\begin{array}{l}L G V \\
n=3\end{array}$ & $\begin{array}{l}\text { Mixed } \\
\text { Infections } \\
n=15\end{array}$ \\
\hline $\begin{array}{l}\text { Single Infections: } \\
\text { Syphilis } \\
\text { Chancroid } \\
\text { Genital herpes } \\
\text { Donovanosis } \\
\text { LGV }\end{array}$ & $\begin{array}{r}30 \\
12 \\
9 \\
9 \\
3\end{array}$ & 1 & $\begin{array}{l}9 \\
8 \\
1 \\
1\end{array}$ & $\begin{array}{l}7 \\
1 \\
7\end{array}$ & $\begin{array}{l}1 \\
1 \\
5\end{array}$ & 2 & $\begin{array}{l}6 \\
2 \\
3\end{array}$ \\
\hline $\begin{array}{l}\text { Mixed Infections: } \\
\text { Syphilis + chancroid } \\
\text { Syphilis + LGV } \\
\text { Syphilis + donovanosis } \\
\text { Syphilis + genital herpes } \\
\text { Chancroid + LGV } \\
\text { Syphilis + chancroid + donovanosis } \\
\text { No pathogens detected }\end{array}$ & $\begin{array}{r}8 \\
2 \\
1 \\
1 \\
1 \\
1 \\
23\end{array}$ & 2 & $\begin{array}{r}1 \\
11\end{array}$ & $\begin{array}{l}1 \\
5\end{array}$ & 3 & 1 & $\begin{array}{l}1 \\
2\end{array}$ \\
\hline
\end{tabular}

of $>1: 16$, positive Treponema pallidum haemagglutination assay (TPHA) and typical clinical appearances of condylomata lata.

\section{Statistical analysis}

The index of suspicion and diagnostic accuracy of the clinical assessment of the ulcers were calculated by the method described by Lightstone et $a l^{6}$ : the predictive values and diagnostic efficiency were determined as in Fast et al. ${ }^{7}$ Because mixed infections were common in our population, the following assumptions were made in determining $A, B$, $C$ and $D^{7}$ for the calculation of the various diagnostic parameters. Thus:

(A) The number of correct clinical diagnoses confirmed by laboratory tests. Mixed infections were excluded from this assessment.

(B) The number of incorrect positive clinical diagnoses determined by the identification of a causative agent other than that suspected clinically. In laboratory confirmed mixed infections a single correct clinical diagnosis was not classified as incorrect.

(C) The number of incorrect negative clinical diagnoses: identification of a cause other than the clinical diagnosis. Mixed infections diagnosed clinically were not included.

(D) Clinical and laboratory negative cases: A negative clinical diagnosis correctly diagnosed as not the entity in question. Mixed infections diagnosed clinically were excluded and laboratory confirmed mixed infections were included in this assessment.

Mixed infections were also analysed as a separate clinical entity. Scabies cases were assessed as correct clinical diagnoses.

The diagnostic parameters were calculated thus:

$$
\begin{array}{ll}
\text { Index of suspicion } & =\frac{A+B}{A+C} \times 100 \\
\text { Diagnostic accuracy } & =\frac{A}{A+B+C} \times 100
\end{array}
$$

Positive predictive value $=\frac{A}{A+B} \times 100$

$$
\begin{aligned}
& \text { Negative predictive value }=\frac{D}{C+D} \times 100 \\
& \text { Diagnostic efficiency }=\frac{A+D}{A+B+C+D} \times 100
\end{aligned}
$$

\section{Results}

A single clinical diagnosis was made in 85 men and 91 women with GUD. In the remaining 15 men and nine women, the clinical appearances of the ulcers were atypical and suggestive of mixed infections.

Comparisons between clinical and laboratory diagnoses in men and women are shown in tables 1 and 2 and the index of suspicion, diagnostic accuracy and efficiency and predictive values in table 3 . The diagnostic efficiency and both positive and negative predictive values for almost all causes of GUD were higher in women than in men. In men the diagnostic accuracies were; donovanosis $63 \%$, chancroid $42 \%$, genital herpes $39 \%$, primary syphilis $32 \%$ and in women, secondary syphilis $94 \%$, donovanosis $83 \%$, genital herpes $60 \%$, primary syphilis $58 \%$, chancroid $57 \%$. The indices of suspicion were, in men: genital herpes $178 \%$, chancroid $170 \%$, donovanosis $117 \%$, mixed infections $93 \%$, primary syphilis $38 \%$ and in women, genital herpes $167 \%$, donovanosis $120 \%$, secondary syphilis $94 \%$, primary syphilis $90 \%$, chancroid $83 \%$, and mixed infections $45 \%$. In 14 men and 13 women with proven mixed infections, syphilis was confirmed by laboratory tests in all but one of the men and one of the women. In this group the diagnostic accuracy was very low- $8 \%$ in men and $14 \%$ in women.

Amongst the men, primary syphilis was associated with a low negative predictive value and chancroid, genital herpes and mixed infections with a low positive predictive value. In men and women with either primary or secondary syphilis, darkfield microscopy was positive in $18(42 \%)$ and 17 $(39 \%)$ respectively. Syphilis was diagnosed by this technique alone in 10 of the men and 4 of the women-in 5 of these men and 4 
Table 2 Clinical and laboratory diagnosis in 100 women with genital ulcer disease

\begin{tabular}{|c|c|c|c|c|c|c|c|c|c|c|}
\hline \multirow[b]{2}{*}{ Laboratory diagnosis } & \multirow[b]{2}{*}{ Number } & \multicolumn{9}{|c|}{ Clinical diagnosis } \\
\hline & & $\begin{array}{l}\text { Secondary } \\
\text { syphilis } \\
n=19\end{array}$ & $\begin{array}{l}\text { Primary } \\
\text { syphilis } \\
n=9\end{array}$ & $\begin{array}{l}1^{\circ} / 2^{\circ} \\
\text { syphilis } \\
n=3\end{array}$ & $\begin{array}{l}\text { Genital } \\
\text { herpes } \\
n=25\end{array}$ & $\begin{array}{l}\text { Donovanosis } \\
n=16\end{array}$ & $\begin{array}{l}\text { Chancroid } \\
n=14\end{array}$ & $\begin{array}{l}L G V \\
n=3\end{array}$ & $\begin{array}{l}\text { Scabies* } \\
n=2\end{array}$ & $\begin{array}{l}\text { Mixed } \\
\text { infections } \\
n=9\end{array}$ \\
\hline $\begin{array}{l}\text { Single Infections: } \\
\text { Secondary syphilis } \\
\text { Primary syphilis } \\
1^{\circ} / 2^{\circ} \text { syphilis } \\
\text { Genital herpes } \\
\text { Donovanosis } \\
\text { Chancroid } \\
\text { LGV }\end{array}$ & $\begin{array}{r}19 \\
11 \\
2 \\
12 \\
10 \\
12 \\
5\end{array}$ & 16 & 7 & 2 & $\begin{array}{r}3 \\
12 \\
2 \\
1\end{array}$ & $\begin{array}{c}1 \\
10\end{array}$ & $\begin{array}{l}8 \\
2\end{array}$ & 2 & & $\begin{array}{l}2 \\
1\end{array}$ \\
\hline $\begin{array}{l}\text { Mixed Infections: } \\
1^{\circ} \text { syphilis + donovanosis } \\
1^{\circ} \text { syphilis + genital herpes } \\
1^{\circ} \text { syphilis + LGV } \\
1^{\circ} 2^{\circ} \text { syphilis + chancroid } \\
2^{\circ} \text { syphilis + genital herpes } \\
2^{\circ} \text { syphilis + chancroid } \\
2^{\circ} \text { syphilis + LGV + donovanosis } \\
2^{\circ} \text { syphilis + donovanosis + genital } \\
\text { herpes } \\
\text { Chancroid + genital herpes } \\
\text { No pathogens detected }\end{array}$ & $\begin{array}{r}3 \\
2 \\
1 \\
1 \\
2 \\
1 \\
1 \\
1 \\
1 \\
16\end{array}$ & 2 & & 1 & $\begin{array}{l}2 \\
1 \\
1\end{array}$ & $\begin{array}{l}1 \\
1\end{array}$ & 4 & 1 & 2 & $\begin{array}{l}1 \\
1 \\
4\end{array}$ \\
\hline
\end{tabular}

^Scabies cases assessed as correct clinical diagnosis in calculations.

women, darkfield microscopy was positive and all serological tests for syphilis (STS) were negative.

The most common clinical diagnosis in men was chancroid.(36) Laboratory diagnoses in these cases were: syphilis 9 , chancroid 8, no pathogens 11 and others 8 . Amongst men with a clinical diagnosis of genital herpes(22) and mixed infections,(15) syphilis was confirmed in 7 and 6 respectively. Amongst women genital herpes(25) was the commonest clinical diagnosis and was confirmed in 14 including two with mixed infections; secondary syphilis(19) was the next most common single clinical diagnosis and was confirmed in 18 including two with concomitant genital herpes.

In the 23 men in whom no pathogens were detected, chancroid and genital herpes were the most likely clinical diagnosis in the majority, (16) and donovanosis,(3) syphilis(2) and mixed infections(2) in the remainder. In the 16 women in whom no pathogens were isolated, chancroid and genital herpes were diagnosed in seven, mixed infections in four, and scabies in two-TPHA and RPR tests were positive in 5 although only 2 , both with mixed infections, had ulcers suggestive of syphilis. Inguinal lympadenopathy was detected in 62 of the men and 55 of the women and was observed in association with all the STD causes of GUD although only

Table 3 Comparison of clinical and laboratory diagnosis in men (M) and women (W) with genital disease

\begin{tabular}{|c|c|c|c|c|c|c|c|c|c|c|}
\hline \multirow[b]{2}{*}{ Diagnosis } & \multicolumn{2}{|c|}{$\begin{array}{l}\text { Index of } \\
\text { suspicion } \\
\%\end{array}$} & \multicolumn{2}{|c|}{$\begin{array}{l}\text { Diagnostic } \\
\text { accuracy } \\
\%\end{array}$} & \multicolumn{2}{|c|}{$\begin{array}{l}\text { Positive } \\
\text { predictive } \\
\text { value } \\
\%\end{array}$} & \multicolumn{2}{|c|}{$\begin{array}{l}\text { Negative } \\
\text { predictive } \\
\text { value } \\
\%\end{array}$} & \multicolumn{2}{|c|}{$\begin{array}{l}\text { Diagnostic } \\
\text { efficiency } \\
\%\end{array}$} \\
\hline & $\mathbf{M}$ & $\mathbf{W}$ & $\mathbf{M}$ & W & $\mathbf{M}$ & W & $M$ & $\mathbf{W}$ & $\mathbf{M}$ & $\mathbf{W}$ \\
\hline $\begin{array}{l}\text { Primary Syphilis } \\
\text { Secondary syphilis } \\
\text { Donovanosis } \\
\text { Chancroid } \\
\text { Genital Herpes } \\
\text { Mixed infections } \\
\text { LGV }\end{array}$ & $\begin{array}{r}38 \\
117 \\
170 \\
178 \\
93 \\
66\end{array}$ & $\begin{array}{r}90 \\
94 \\
120 \\
83 \\
167 \\
45 \\
40\end{array}$ & $\begin{array}{r}32 \\
63 \\
42 \\
39 \\
8 \\
66\end{array}$ & $\begin{array}{l}58 \\
94 \\
83 \\
57 \\
60 \\
14 \\
40\end{array}$ & $\begin{array}{r}89 \\
-71 \\
47 \\
44 \\
15 \\
100\end{array}$ & $\begin{array}{r}78 \\
100 \\
83 \\
80 \\
60 \\
40 \\
100\end{array}$ & $\begin{array}{l}64 \\
98 \\
94 \\
96 \\
83 \\
98\end{array}$ & $\begin{array}{r}95 \\
98 \\
100 \\
94 \\
100 \\
89 \\
96\end{array}$ & $\begin{array}{l}68 \\
95 \\
79 \\
83 \\
70 \\
98\end{array}$ & $\begin{array}{l}93 \\
99 \\
97 \\
92 \\
89 \\
86 \\
96\end{array}$ \\
\hline
\end{tabular}

infrequently with donovanosis. Buboes were present in 10 men and 4 women: no pathogens were detected in four of these men and two women.

\section{Discussion}

The findings of this study demonstrate many of the difficulties in assessing the causes of GUD in the developing world. In Durban this problem is compounded by both the high incidence of all the sexually transmitted causes of GUD, mixed infections and atypical presentation of longstanding disease. Proper evaluation of the accuracy of clinical diagnosis in GUD requires reference tests with a high degree of sensitivity and specificity. However, for most of the important causes of GUD, tests that meet these criteria are limited. For example, in populations with a significant prevalence of syphilis, low sensitivities for darkfield microscopy to demonstrate Treponema pallidum have been reported from the Gambia, ${ }^{8}$ Johannesburg, ${ }^{9}$ and Durban ${ }^{10}$; Haemophilus ducreyi was cultured from less than $12 \%$ of 5409 cases of chancroid reported in the USA since $1981^{11}$; low sensitivities are reported for the isolation of HSV from typical lesions both in men with genital ulcers ${ }^{12}(52 \%)$ and women with either first episode $(55 \%)$ or symptomatic recurrences $^{13}(34 \%)$; the causative organism in donovanosis, Calymmatobacterium granulomatis, has not been isolated by culture techniques since $1962 .{ }^{14}$ Despite the recognition of GUD as a major risk factor in HIV transmission, developments in rapid reliable tests for GUD have been limited. Diagnostic tests are improving with time but few STD clinics in resource poor settings undertake investigations for GUD other than STS.

In this study the clinical diagnostic accuracy was greatest for donovanosis and secondary syphilis. We found a high degree of concordance between a clinical diagnosis of donovanosis and detection of Donovan bodies by the RapiDiff method. ${ }^{15}$ Donovanosis 
ulcers tended to bleed readily to the touch and were considerably larger and not associated with inguinal lymphadenopathy when compared to other causes of GUD. The RapiDiff test was introduced into routine use in this clinic during 1988 and was followed by an increase in reported cases. The technique requires care in the collection of specimens and preparation of slides and our results may reflect expertise acquired through the recognition of a current epidemic of donovanosis in Durban. ${ }^{16}$

Secondary syphilis was readily distinguished from other causes of GUD and was more frequent in women than in men. Despite extensive multiple lesions of vulval condylomata lata in some cases, mucosal surfaces were disrupted much less than in other causes of GUD. Overall, in men and women with primary and secondary syphilis, darkfield microscopy was positive in $42 \%$ of the men and $39 \%$ of the women. Whilst this technique is highly specific and invariably recommended for the diagnosis of primary and secondary syphilis, it is not used routinely in this clinic because of both lack of personnel and constraints of time. Operation of a darkfield service requires training, expertise, and precision and maintenance of a special microscope and at present is not feasible logistically in busy clinics where resources remain limited. If darkfield microscopy had not been undertaken and a single positive STS chosen as the criterion for a laboratory diagnosis of syphilis in our study, only five men and four women would have been incorrectly diagnosed as not having syphilis. It should be added that a positive STS does not always indicate active infection with syphilis and in areas with a high prevalence of syphilis, such as Durban, positive STS are common and do not differentiate between either the various stages of syphilitic infection or whether or not treatment has been given. In theory, this could have led to an overestimate of the true prevalence of syphilis in our study. However, we only used both TPHA and RPR (and then at a titre of $>16$ ) positivity as criteria for the diagnosis of secondary syphilis because of the possibility that competitive inhibition of the fluorescent treponemal antibody absorption (FTA-ABS) test for 1gM by high levels of $1 \mathrm{gG}$ had occurred in some cases. ${ }^{2}$ We felt that secondary syphilis was the most readily recognised cause of GUD clinically in this study and that the likelihood of misclassifying cases as either latent or late syphilis rather than secondary syphilis was minimal. This is borne out by our finding of only one incorrect clinical diagnosis of secondary syphilis. Overall syphilis was probably underdiagnosed because of the low sensitivity of tests for early lesions of primary syphilis-in our case, darkfield microscopy and FTA-ABS 1gM. Our policy is, therefore, to treat all GUD cases with positive STS with benzathine penicillin 2.4 mega units by a single intramuscular injection and to regard all ulcers as suspicious of syphilis unless clinical appearances are entirely typical of another cause.
The true prevalence of chancroid was probably underestimated in this study. In uncircumcised men, chancroid ulcers, particularly in the subpreputial area, heal with scarring, fibrosis and phimosis. Because of both difficulty and in some cases inability to retract the foreskin, complete visual inspection and proper clinical assessment was possible in only 84 of the men. ${ }^{3}$ Despite using two culture media, confirmed cases tended to be grouped together in order of attendance suggesting variation in either the processing of specimens or batches of culture media.

If the sensitivities of the tests for primary syphilis, chancroid and genital herpes in this study are accepted as low, the true proportion of mixed infections was probably considerably higher than that detected. The most frequent confirmed diagnosis in mixed infections were, in men-syphilis 13, chancroid 9, donovanosis 2, LGV 2 and in women-syphilis 12 , genital herpes 6 , donovanosis 6. Although empirical treatment to cover syphilis and chancroid is justified in men, the 'management of women is less clearcut. The most likely clinical diagnoses in both sexes in whom no pathogens were detected were chancroid and genital herpes. These ulcers are usually small and differentiation between them may be difficult. If either are suspected, the benefits of giving treatment for chancroid probably outweigh inappropriate antibiotic therapy for genital herpes. Although this strategy may encourage patients with recurrent genital herpes to reattend unnecessarily, the consultation could be used to modify riskful sexual practices ${ }^{17}$ at a time of particular vulnerability to HIV infection. The diagnostic accuracy, positive predictive value and index of suspicion of $39 \%$, $44 \%$ and $178 \%$ in men with genital herpes suggests under-diagnosis by laboratory tests although over-diagnosis by the observer cannot be discounted. Appearances of genital herpes in Durban are often atypical and may follow secondary infection due to poor hygiene or the application of local antiseptics which erode and deepen the ulcer bed. Although elsewhere in Africa data have been limited, ${ }^{18}$ reports from Rwanda ${ }^{19}$ and $\mathrm{Uganda}^{20}$ indicate that, as in Durban, genital herpes is a significant problem.

LGV ulcers were usually small and single. Whilst the prevalence of LGV was low and our numbers small, LGV probably presents less of a theoretical risk for HIV transmission than other causes of GUD in which lesions are more extensive. Inguinal lymphadenopathy is a consistent finding in LGV but was common in both men and women with all causes of GUD except donovanosis in this study and therefore of minimal help in making a correct clinical diagnosis.

Local treatment guidelines for GUD will need to take into account the finding that all the STD causes of GUD are prevalent in Durban and that donovanosis and secondary syphilis are readily distinguished clinically. In the absence of rapid diagnostic tests, management strategies for GUD could be based both 
on clinical appearances and size of the ulcers and we would make the following suggestions: only very superficial ulcers or vesicles should be diagnosed as genital herpes; for larger ulcers, that is, ulcers of greater than approximately seven mms diameter, treatment for syphilis and donovanosis should be given. For smaller lesions treatment for syphilis and for chancroid/donovanosis with cotrimoxazole/erythromycin would be effective and would also cure most cases of LGV. However, the possible emergence of $H$ ducreyi strains resistant to cotrimoxazole and variability in the efficacy of treatment for chancroid in HIV seropositive patients will need to be observed closely. Without knowledge of a patient's HIV serostatus, first line treatment for GUD should ideally be effective for both HIV seropositive and seronegative individuals. Reports of syphilis not responding to single dose benzathine penicillin, ${ }^{21}$ the treatment of choice for syphilis in Sub-Saharan Africa, are worrying and prospective studies are required to investigate the natural history of syphilis in immuno-compromised individuals. Furthermore, just as genital herpes may cause extensive lesions in AIDS, the possibility of unusual presentations of chancroid, donovanosis and LGV should be considered.

Any intervention that lowers the prevalence of GUD is likely to lessen the spread of HIV infection and all developing countries with a high prevalence of GUD should draw up specific management guidelines to improve GUD control. Primary health care workers in these countries will need to be aware of the difficulties in making a correct clinical diagnosis and would undoubtedly benefit from educational workshops that focus on GUD. Although commercial sex workers with GUD have been identified in Kenya as an important core of potential HIV transmitters, ${ }^{22}$ in Durban uncircumcised men with GUD are the most likely "superspreader" group and need to be targeted specifically. ${ }^{17}$ Because of the difficulties in diagnosing genital ulcers in uncircumcised men, antibiotic therapy should be supplemented with counselling and health education directed towards both improving standards of personal hygiene ${ }^{23}$ and reinforcing the message of the potential risks of sexual intercourse in the presence of genital lesions. Specific targeting of core groups has often led to fears of stigmatisation but most uncircumcised men with GUD would be unlikely to be identified as such other than during physical examination by a health care worker. However, this targeting might not be so easy to implement if the move to decentralise STD services in resource-poor settings continues. The management of uncircumcised men with GUD has never been identified as a priority area and such negative perceptions by primary health care workers might be difficult to change. Indifferent standards in the quality of care in the formal sector have probably reinforced the popularity of traditional healers who undoubtedly see a large number of STD cases. More recently some of these practitioners locally have started to dispense ampicillin and sulpha powders ${ }^{24}$ in sub-therapeutic doses and this practice is likely to further accelerate the emergence of drug-resistant organisms. Any national STD programme targeting GUD should involve close liason with all sectors providing treatment, whether formal or informal. The urgency of such interventions is underpinned by the rapid increase in HIV-1 seroprevalence amongst men attending this clinic from $0 \%$ in early 1987 to $12 \%$ in men in $1990 .{ }^{25}$ Although the evaluation of such interventions directed at GUD will not be straightforward early implementation of such programmes should not be delayed if the very large proportion of HIV infections attributable to GUD are to be contained.

We acknowledge the assistance of all doctors, nursing sisters and health assistants at the Durban City Health STD Clinic, particularly Mr Bernard Zulu.

1 Hayes R, Schulz KF. What proportion of HIV infections are attributable to genital ulcers in sub-Saharan Africa? VIII International Conference on AIDS, Amsterdam 19-24 July 1992. Abstract No. MoC 0029 .

2 O'Farrell N, Hoosen AA, Coetzee KD, van den Ende J. Genital ulcer disease, in women in Durban, South Africa. Genitourin Med 1991;67:322-6.

3 O'Farrell N, Hoosen AA, Coetzee KD, van den Ende J. Genital ulcer disease in men in Durban, South Africa. Genitourin Med 1991;67:327-30

4 O'Farrell N, Windsor I, Becker P. HIV-1 infection among heterosexual attenders at a sexually transmitted diseases clinic in Durban. $S$ Afr Med $\mathcal{f} 1991 ; 80: 17-20$.

5 WHO. Prevention of sexual transmission of human immunodeficiency virus. WHO AIDS Series 6, 1990

6 Lightstone AC, Kopf AW, Garfinkel L. Diagnostic accuracy-a new approach to its evaluation. Arch Dermatol racy-a new approac

7 Fast MW, D'Costa LJ, Nsanze H, et al. The clinical diagnosis of genital ulcer disease in the tropics. Sex Transm nosis of genital ulcer

8 Mabey DCW, Wall RA, Bello CSS. Aetiology of genital ulceration in the Gambia. Genitourin Med 1987;63:312-5.

9 Duncan MO, Ballard RC, Bilgeri YR, Fehler HG. Sexually acquired genital infections in urban black women. Southerm African foumal of Sexually Transmitted Diseases 1984;4:23-7.

10 Coovadia YM, Kharsany A, Hoosen A. The microbial aetiology of genital ulcers in black men in Durban, South Africa. Genitourin Med 1985;61:266-9.

11 Morse SA. Chancroid and Haemophilus ducreyi. Clin Microbiol Rev 1989;2:137-57.

12 Brown ST, Jaffe HW, Zaidi A, et al. Sensitivity and specificity of diagnostic tests for genital infection with herpes virus hominis. Sex Transm Dis 1979;6:10-13

13 Koutsky LA, Stevens CE, Holmes KK, et al. Underdiagnosis of genital herpes by current clinical and viral isolation procedures. N Engl $₹$ Med 1992;326:1533-9.

14 Goldberg J. Studies on granuloma unguinale V. Isolation of a bacterium resembling Donovania granulomatis from the faeces of a patient with granuloma inguinale. Br 7 Venereal Dis 1962;38:99-102.

15 O'Farrell N, Hoosen AA, Coetzee KD, van den Ende J. A rapid stain for the diagnosis of granuloma inguinale. Genitourin Med 1990;66:200-1.

16 O'Farrell N. Trends in reported cases of donovanosis in Durban, South Africa. Genitourin Med 1992;68: 366-9.

17 O'Farrell N, Hoosen AA, Coetzee KD, van den Ende J. Sexual behaviour in Zulu men and women with genital ulcer disease. Genitourin Med 1992;68:245-8.

18 Osoba AO. Sexually transmitted diseases in tropical Africa. A review of the present situation. Br $\mathcal{f}$ Venereal Dis 1981;57:89-94.

19 Bogaerts J, Ricart CA, Van Dyck E, Piot P. The aetiology of genital ulceration in Rwanda. Sex Transm Dis 1989; 16:123-6.

20 Kamya RM, Nsubuga P, Hellman N. The aetiology of genital ulcer disease in Uganda. VI International Conference on AIDS in Africa. Dakar 1991 (Abstract WA 149).

21 Hook EW. Syphilis and HIV Infection. $\mathcal{F}$ Infect Dis 1989; 160:530-4.

22 Kreiss JK, Coombs R, Plummer F, et al. Isolation of human immunodeficiency virus from genital ulcers in Nairobi prostitutes. F Infect Dis 1989;160:380-4.

23 O'Farrell N. Soap and water prophylaxis for limiting genital ulcer disease and HIV-1 infection in men in subSaharan Africa. Genitourin Med 1993;69:297-300.

24 Koloko P, Zokwe B, Green EC, Dupree JD. Ethnomedical practices of significance to the spread and premedical practices of significance to the spread and prevention of Hiv in Southern Africa. DXth International No PO-C03-2610

25 Annual Report of the Medical Officer of Health for Durban 1991. 